\title{
Learning application of kangguru method as treatment in weight low storage baby at home
}

\author{
Bina Melvia Girsang ${ }^{1 *}$, Fajar Utama Ritonga ${ }^{2}$, Samerdanta Sinulingga $^{3}$ \\ ${ }^{1}$ Faculty of nursing, Universitas Sumatera Utara \\ ${ }^{2}$ Faculty of Social Sciences and Political Sciences, Social welfare science, Universitas \\ Sumatera Utara \\ 3 Faculty of Cultural Sciences, Tourism, Universitas Sumatera Utara \\ *Email: binamelvia@usu.ac.id
}

\begin{abstract}
Mothers who take care of the kangaroo method feel more confident in caring for their babies compared to mothers who do not take care of the kangaroo method. Kangaroo care methods also increase the closeness of the mother with her baby (bonding attachment), reduce feelings of stress to the mother as well as to the baby, and make the mother and baby more calm and relaxed. Mother's confidence will improve along with the increase in the ability of mothers to care for their babies. Based on information about the Purba Horison Village, the main problems and alternative solutions were found, namely the lack of means in terms of electronic communication more or less to make the community lack of knowledge in terms of health that also affects family parenting patterns and living standards of the local community. For this reason, counseling and training in the health sector are needed to increase community knowledge that can improve the quality of life of the Purba Horison village community.
\end{abstract}

Keywords: Kangaroo method, counseling, care

\begin{abstract}
Abstrak
Ibu yang melakukan perawatan metode kanguru merasa lebih percaya diri dalam merawat bayinya dibandingkan dengan ibu yang tidak melakukan perawatan metode kanguru. Perawatan metode kanguru juga meningkatkan kedekatan ibu dengan bayinya (bonding attachment), mengurangi perasaan stres pada ibu sebagaimana halnya pada bayi, serta membuat ibu dan bayi lebih tenang dan rileks. Kepercayaan diri ibu akan membaik seiring dengan peningkatan kemampuan ibu dalam merawat bayinya. Berdasarkan informasi mengenai Desa Purba Horison, didapati masalah utama beserta alternatif pemecahan masalah yaitu minimnya sarana dalam hal komunikasi secara elektronik sedikit banyaknya membuat masyarakat minim pengetahuan dalam hal kesehatan yang turut mempengaruhi pola asuh keluarga serta standar hidup masyarakat setempat. Untuk itu, diperlukan penyuluhan dan pelatihan dalam bidang kesehatan untuk meningkatkan pengetahuan masyarakat yang dapat meningkatkan kualitas hidup masyarakat desa Purba Horison.
\end{abstract}

Kata Kunci: Metode kanguru, penyuluhan, perawatan

\section{PENDAhuluan}

Secara khusus angka kematian neonatus di Asia Tenggara adalah 39 per 1000 kelahiran hidup (Karen., et al, 2006). Kematian dan resiko komplikasi pada bayi baru lahir dapat dicegah dengan peran serta aktif kader posyandu setempat untuk menjadi kelompok pendukung bagi masyarakat disekitarnya, karena kader dapat menjadi fasilitator terdekat yang mudah diakses oleh masyarakat. Oleh karena itu kelompok kader posyandu yang akan memberikan dukungan khususnya pada ibu hamil harus dibekali dengan ilmu dan teknologi tepat guna sehingga layanan 
pada ibu hamil dalam mencegah kasus kematian bayi baru lahir dapat dicegah dengan metode perawatan kangguru yang dapat memfasilitasi bonding attachment antara orang tua dengan bayi. Permasalahan yang dihadapi oleh kelompok kader posyandu di desa Nagori Purba Horison, Kecatan Haranggaol Horison, antara lain masih rendahnya cakupan layanan pada ibu hamil dan informasi tentang persiapan perawatan bayi baru lahir. Cakupan layanan yang rendah ini disebabkan oleh sumber daya kader baik materil maupun dari segi jumlah yang masih kurang dibandingkan tugas yang harus diemban oleh seorang kader yang bekerja dengan sukarela. Minimnya tenaga kesehatan seperti dokter dan bidan yang mendampingi kelompok posyandu.

Hasil penelitian membuktikan bahwa jika tidak terdapat masalah medis, maka tidak ada alasan untuk memisahkan ibu dari bayinya. (Yamauchi and Yamanouchi 1990; Buranasin 1991; Oslislo and Kaminski 2000). Semakin seringnya ibu melakukan kontak fisik langsung (skin-toskin contact) dengan bayi akan membantu menstimulasi hormon prolaktin dalam memproduksi ASI (Hurst 1997), dengan demikian fenomena tersebut diatas perlu disiasati dengan sosialisasi manfaat perawatan metode kangguru (PMK) pada Ibu yang sedang hamil pada kunjungan antenatal. Bayi dibiarkan menyusu sambil dipeluk dan diselimuti. Menyusui bayi dengan metode tersebut juga akan merangsang reflek menyusu bayi serta kontak kulit menstabilkan suhu tubuh bayi, kadar gula darah bayi lebih tinggi, lebih jarang menangis, lebih mudah untuk menyusui untuk jangka panjang, dan menimbulkan perasaan aman bagi bayi. (Mary., et al, 2007; Kaur et al, 2002 ; Paramitha Rahdian, 2007).

Purba Horison merupakan salah satu desa yang berada di kecamatan Haranggaol yang terdapat pada Kabupaten Simalungun. Desa Purba Horison Terdapat 4 Dusun yakni Dusun Silumbak, Dusun Bangun Purba, Dusun Liang Nakka dan Dusun Halaotan. Dengan Jumlah penduduk 743 jiwa dari 191 kepala keluarga berdasarkan rekapitulasi data 2018. Dari pengamatan yang kami lakukan ketika sampai di lokasi, infrastruktur yang tidak memadai (jalan yang tidak bagus dan berbatuan) di Desa Purba Horison sehingga menghambat kegiatan warga untuk beraktifitas. Penghasilan pokok warga Purba Horison dari bercocok tanam pada ladang bawang, kebun kopi dan manga. Pada sektor kesehatan dan lingkungan, masyarakat Purba Horison bisa dikatakan sudah mendapatkan pelayanan yang baik, karena setiap minggunya Bidan Desa datang ke dusun-dusun untuk memeriksa kesehatan ibu-ibu hamil, balita dan lansia. Bidan Desa juga mengajak masyarakat dan lansia senam bersama. Namun Desa tersebut hanya memiliki 1 buah Pusat Kesehatan Desa yang berjarak lebih kurang $3 \mathrm{Km}$, sedangkan untuk PUSKESMAS terletak di pusat kecamatan yang berjarak lebih kurang $7 \mathrm{Km}$ dari desa tersebut. Kekurangan tenaga kesehatan dan fasilitas kesehatan dengan letak yang cukup jauh maka dirasakan perlu untuk membuat pembelajaran kepada kader, bidan anggota masyarakat tentang metode kangguru sebagai perawatan pada bayi berat lahir rendah yang stabil di rumah.

Kuliah Kerja Nyata $(\mathrm{KKN})$ hakekatnya merupakan perwujudan dari salah satu Tridarma Perguruan Tinggi, yakni pendidikan dan pengajaran yang memiliki point penting dalam Tridarma Perguruan Tinggi, pendidikan dan pengajaran ini merupakan proses pembelajaran untuk menciptakan bibit-bibit unggul dari suatu pergurusn tinggi yang akan membawa bangsa ini ke arah yang lebih maju. Penelitian dan pengembangan juga sangat penting bagi kemajuan bangsa dan negara. Dari penelitian dan pengabdiana ini mahasiswa mampu mengembangkan ilmu dan teknologi, dan mahasiswa harus cerdas, kritis dan kreatif dalam menjalankan perannya sebagai agent of change. Pengabdian kepada masyarakat yang merupakan kegiatan positif dan bersifat lintas disiplin (interdispliner) serta komponen keilmuan, teknologi, dan seni secara aplikatif guna membantu kehidupan masyarakat, utamanya dipedesaan. Dengan KKN diharapkan para mahasiswa dapat membantu menghadapi kesulitan-kesulitan yang dihadapi sesuai dengan bidang keilmuan masing-masing. Melalui KKN ini pula mahasiswa dapat membantu merealisasikan program-program pemerintah dalam rangka melaksanakan pemerataan pembangunan di desa. 


\section{METODE PELAKSANAAN}

\subsection{Kegiatan pengabdian kepada masyarakat}

1. Bekerja sama dengan pihak kader setempat untuk mengumpulkan target sasaran

2. Pelaksanaan penyuluhan, membimbing, dan mempraktekkan cara perawatan metode kangguru dengan kain tari

3. Menggunakan media alat kain tari dan melakukan simulasi dan redemonstrasi perawatan metode kangguru

4. Menjelaskan Pemanfaatan kain panjang dapat digunakan untuk perawatan metode kangguru dengan prinsip skin to skin contact Metode pelaksanaan berisi metode-metode pelaksanaan yang sesuai teori dari buku ataupun artikel yang disitasi. Sitasi dilarang menggunakan akses dari sebuah website. Metode dituliskan secara rinci dan jelas. Jika perlu bisa digambarkan diagram alir untuk metode pelaksanaan sama dengan aturan untuk membuat diagram alir dari suatu algoritma.

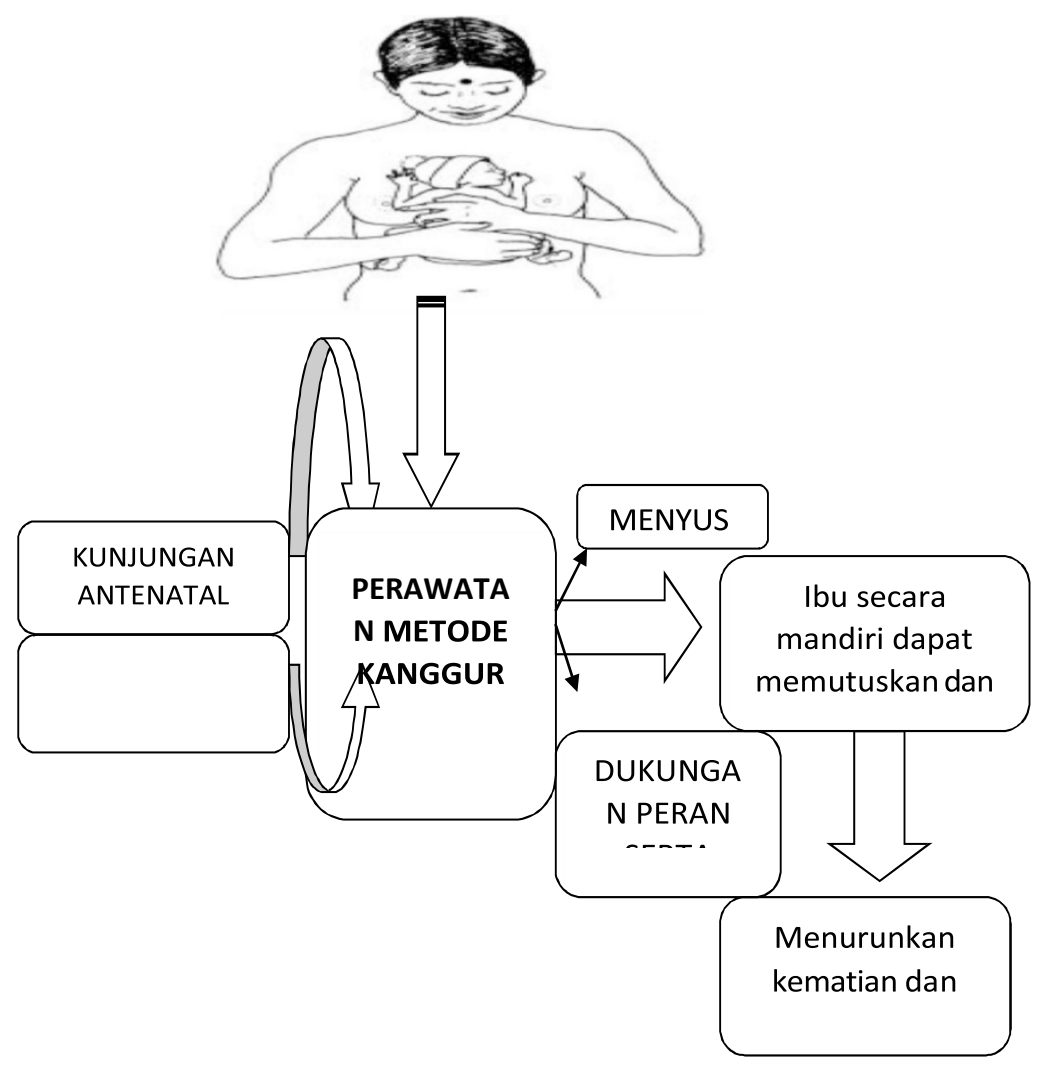

Gambar. 3.1. Gambaran Ipteks 
Tabel 3.2. Standar operasional prosedur perawatan metode kangguru

\begin{tabular}{|c|c|c|}
\hline Waktu & Kegiatan Penyuluhan & Kegiatan Peserta \\
\hline 5 menit & $\begin{array}{l}\text { Pembukaan: } \\
\square \text { Membuka kegiatan dengan mengucapkan salam } \\
\square \text { Memperkenalkan diri } \\
\square \text { Menjelaskan tujuan daripenyuluhan } \\
\square \text { Menyebutkan materi atau pokok bahasan yang akan } \\
\text { diberikan } \\
\square \text { Menyampaikan kontrak waktu }\end{array}$ & $\begin{array}{l}\square \text { Menjawab salam } \\
\square \text { Mendengar dan } \\
\text { memperhatikan }\end{array}$ \\
\hline 25 menit & $\begin{array}{l}\text { Pelaksanaan: } \\
\square \text { Menggali pengetahuan peserta tentang perawatan } \\
\text { metode kangguru } \\
\square \text { Memberikan reinforcement danmeluruskan konsep } \\
\square \text { Menjelaskan tentang pengertian perawatan metode } \\
\text { kangguru } \\
\square \text { Menjelaskan waktu pelaksanaan } \\
\text { perawatan metode kangguru } \\
\square \text { Menjelaskan manfaat dariperawatan metode kangguru } \\
\square \text { Menjelaskan fasilitas yangdiperlukan dalam perawatan } \\
\text { metode kangguru } \\
\square \text { Menjelaskan posisi perawatan metode kangguru yang } \\
\text { benar } \\
\square \text { Menjelaskan cara pemberian ASI dalam perawatan } \\
\text { metode kangguru } \\
\square \text { Menjelaskan cara merawat bayi dalam metode } \\
\text { kangguru } \\
\square \text { Menjelaskan waktu yang diperlukan dalam perawatan } \\
\text { metode kangguru } \\
\square \text { Menjelaskan } \\
\text { perawatan metode kangguru } \\
\square \text { Menjelaskan } \\
\text { perawatan metode kanguru }\end{array}$ & $\begin{array}{l}\square \text { Mengemukakan } \\
\text { pendapat } \\
\square \text { Mendengar } \\
\text { memperhatikan } \\
\square \text { Memberikan umpan } \\
\text { balik terhadap materi } \\
\text { yang disampaikan }\end{array}$ \\
\hline 15 menit & $\begin{array}{l}\text { Tanya Jawab: } \\
\square \text { Memberikan kesempatan kepada peserta } \\
\text { untuk bertanya tentang materi yang kurang paham } \\
\square \text { Memberikan reinforcement positif } \\
\square \text { Menjawab pertanyaan yangdiajukan }\end{array}$ & $\begin{array}{l}\square \text { Mengajukan pertanyaan } \\
\text { Memperhatikan }\end{array}$ \\
\hline 10 menit & $\begin{array}{l}\text { Evaluasi : } \\
\text { Menanyakan kembali kepada peserta tentang materi } \\
\text { yang telah diberikan dan } \\
\text { reinforcement kepada peserta yang menjawab pertanyaan. }\end{array}$ & $\square$ Menjawab pertanyaan \\
\hline 5 menit & $\begin{array}{l}\text { Penutup : } \\
\square \text { Menjelaskan kesimpulan darimateri penyuluhan } \\
\square \text { Mengucapkan terima kasih danmengucapkan salam }\end{array}$ & $\begin{array}{l}\square \text { Mendengarkan dengan } \\
\text { seksama dan menjawab } \\
\text { salam. }\end{array}$ \\
\hline
\end{tabular}




\section{HASIL DAN PEMBAHASAN}

Para kaum ibu antusias dalam mengikuti pembelajaran metode kangguru dalam perawatan bayi berat lahir rendah stabil di rumah pada tanggal 8 Agustus 2019 di Desa 1 Silumbak, Purba Horison. Beberapa orang ibu ada yang bertanya, dan beberapa orang ibu mampu menjawab pertanyaan seputar topic yang sudah diajarkan
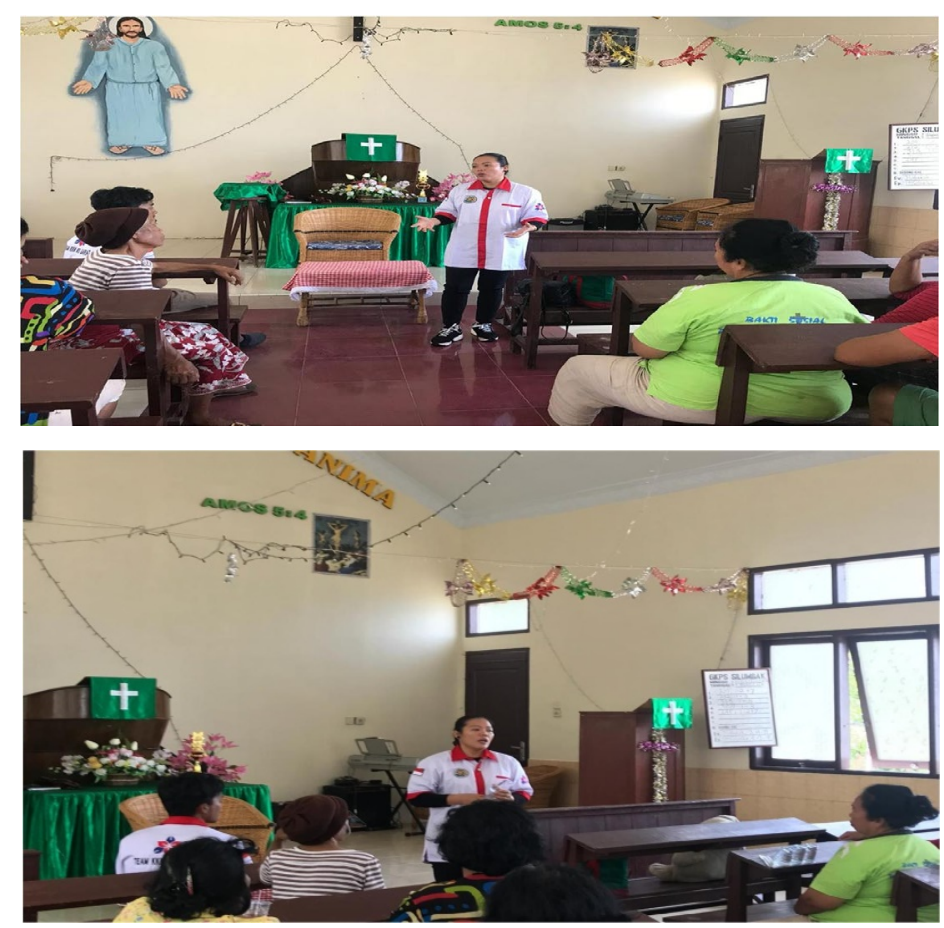

Gambar 3.2. Introduksi Metode Kangguru Sebagai Perawatan BBLR
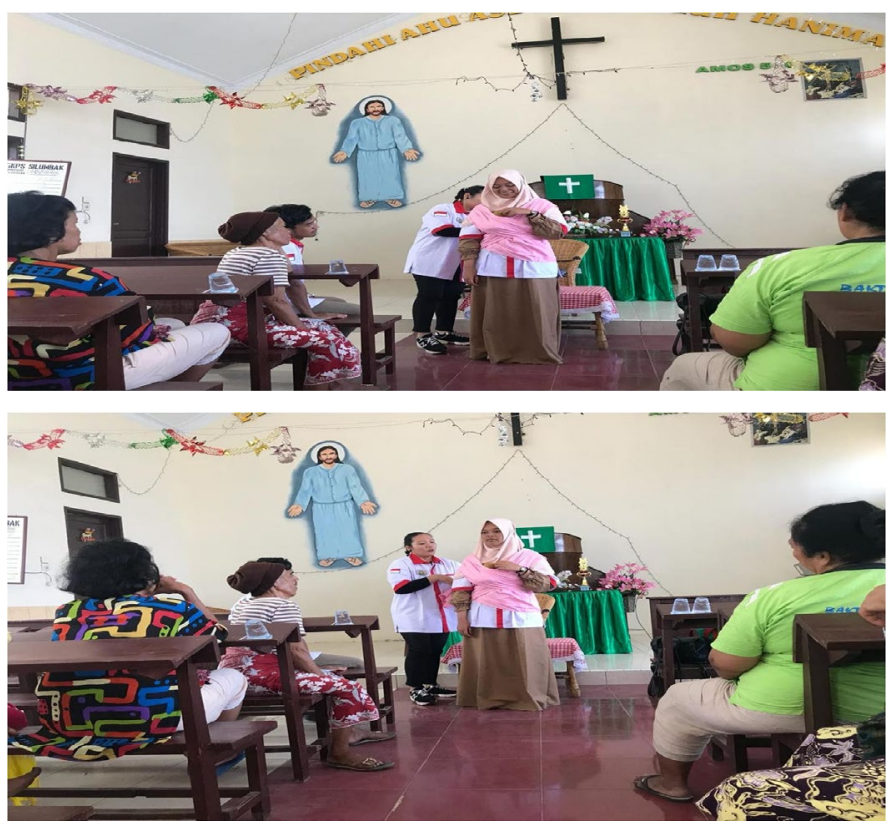

Gambar 3.3. Demontrasi Intervensi Perawatan Metode Kangguru 
Proses pendampingan berjalan dengan baik, sehingga seluruh ibu merasa senang dan merasakan manfaat mendapatkan pengetahuan baru dan dapat dipraktekkan dalam keseharian, sehingga program pemberdayaan perempuan pada sector kesehatan merupakan peta kekuatan yang dapat terus dipertahankan dan ditingkatkan di desa Purba Horison.

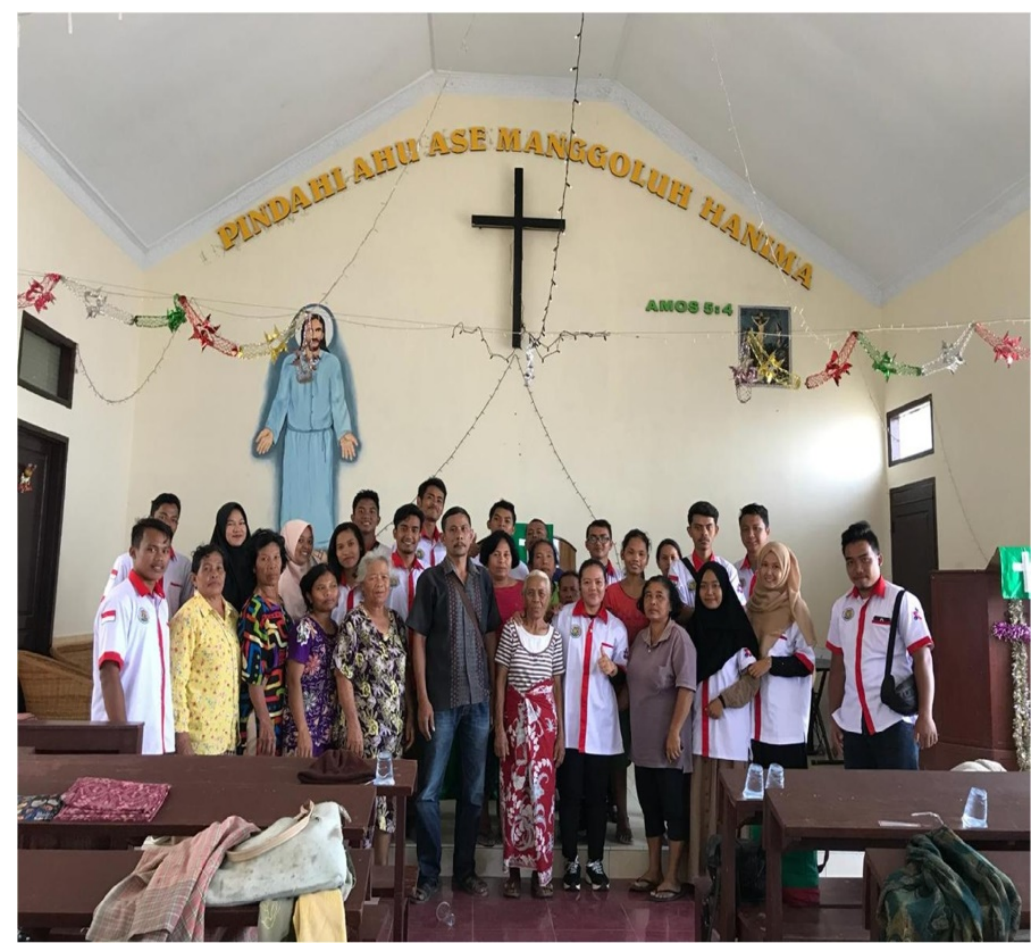

Gambar 3.4. Foto Bersama

\section{KESIMPULAN}

Berdasarkan kegiatan pengabdian pembelajaran metode kangguru sebagai perawatan bayi berat lahir rendah stabil di rumah, disimpulkan bahwa ibu di posyandu teratai merahsangat antusias untuk mengikuti kegiatan dan hal ini merupakan peta kekuatan untuk dapat memberdayakan (women empowering) kelompk masayarakat terutama dalam menurunkan angka kematian bayi berat lahir rendah (BBLR). Penyebaran informasi kesehatan tentang perawatan bayi sejak dini akan membantu ibu untuk mengambil keputusan untuk perawatan kesehatan bayinya.

\section{UCAPAN TERIMAKASIH}

Artikel ini adalah hasil dari Program Pengabdian kepada Masyakarat yang dibiayai oleh BPPTN Universitas Sumatera Utara, sesuai dengan Surat Perjanjian Penugasan Pelaksanaan Pengabdian kepada Masyarakat Program Mono Tahun Dosen Muda, nomor: 331/UN5.2.3.2.1/PPM/2019, tanggal 20 Mei 2019. Tim Pengabdian mengucapkan terima kasih kepada Rektor dan LPPM USU atas dukungan dana dan fasilitas yang diberikan.. 


\section{DAFTAR PUSTAKA}

Alligood, M.R. \& Tomey, A.M. (2006). Nursing theory utilization dan application. (edisi 3). USA : Mosby elsevier.

Affonso, D. D., et al. (1989). Exploration of mother's reactions to the kangaroo method of prematurity care. Neonatal network, 7(6) : 43-51 dalam Dodd

V.L. (2003). Effects kangaroo care in preterm infants. University of Connecticut. . http://www.proquest.umi.com diperoleh tanggal 15 Januari 2014

Anonymous. Kangaroo care. Diunduh dari http://en.wikipedia.org/wiki/kangaroo_care. tanggal 20 Januari 2014

Anonymous. Principles of kangaroo mother care. Perinatal Education Programme. Mother and Baby Friendly Care: Unit 43-44:6/2004. Diakses tanggal 20 Januari 2014

A Randomized, Controlled Trial of Kangaroo Mother care : Result of Follow- Up at 1 Year of Correct Age. (2001). Journal of The American Academy of Pediatrics. 108(5): 1072-1079. Diambil dari http://www.pediatrics.aapublications.org/egi/reprint/108/5/1072 diakses tanggal 20 Januari 2014

Anderson., GC. (1989). Risk in mother-infant separation post birth. Image.21:196-199 Anisio Veloso, (2002). The Impact of Kangaroo Mother Care on Neonatal Mortality in Brazil. PAHO REPORT : Brazil

Arora., S(2008). Kangaroo mother care. Nursing Journal of India, 99 (11): 248-250. Diambil dari http://www.proquest.umi.com diakses pada tanggal 26 September 2014

Badan Pusat Statistik. Survei Sosial dan Ekonomi Nasional. Jakarta: BPS; 2005.

Badr, L.K. (2005). Further psychometric testing and use of the maternal confidence questionnaire. Comprehensive Pediatric Nursing, 28:163-174 http://www.proquest.umi.com diperoleh tanggal 20 Januari 2014

Bakteri berbahaya dalam susu formula. http://saffaaqiqah.wordpress.com. diambil pada tanggal 20 Januari 2014

Barber, C. M., Abernathy, T., Steinmetz, B., \& Charlebois, J.(1997). Using a breastfeeding prevalence survey to identify a population for targeted programs. Canadian Journal of Public Health, 88, 242-245.

Barnes, J., Stein, A., Smith, T., \& Pollock, J. (1997). Extreme attitudes to body shape, social and psychological factors and a reluctance to breast feed. Journal of the Royal Society of Medicine, 90, 551-559.

Bergman, LL Linley, SR Fawcus. Randomized controlled trial of skin-to-skin contact from birth versus conventional incubator for physiological stabilization in 1200- to2199- gram newborns. Acta Paediatr. 93:779-785. 2004. 
Bobak, I.M., Lowdermik, D.L., \& Jensen, M.D. (2005). Keperawatan maternitas. (Edisi 4). Jakarta: Penerbit EGC

Buranasin, B. The effects of rooming-in on the success of breastfeeding and the decline in abandonment of children. Asia Pac J Public Health 1991; 5(3):217-20

Cattaneo A, et al. Kangaroo mother care for low birthweight infants: a randomised controlled trial in different settings. Acta Paediatrica. 1998; 87:976-985.

Charpak N, et al. Kangaroo-mother programme: an alternative way of caring for low birth weight infants. One year mortality in a two-cohort study. Pediatrics, 1994, 94:804- 810.

Conde-Agudelo, A., Diaz-Rossello, J., \& Belizan. Kangaroo mother care to reduce morbidity and mortality in low birthweight infants. Cochrane Database Syst Rev. 2003; (2), CD002771.

Charpak, N., Ruiz-Pelaz, J., \& Figueroa, Z. Influence of feeding patterns and other factors on early somatic growth of healthy, preterm infants in home-based kangaroo mother care: A cohort study. Journal of Pediatric Gastroenterol Nutrition. 2005; 41 (4), 430-437.

Conde-Aguedelo A. Diaz-Rosello JL, Belizan JM. (2003).Kangaroo mother care toreduce morbidity and mortality in low birth weight infant. Cochrane Library.

Charpak N, Ruiz-Pelaez JG, Charpak Y. Rey-Martinez. Kangaroo Mother Program: An Alternative Way of Caring for Low Birth Weight Infants. One year Mortality in a Two Cohort Study. Pediatrics. 1994

Charpak N, Ruiz-Pelaez JG, Figueroa de CZ. Current knowledge of kangaroo mother intervention. Curr Opin Pediatr. 1996;8: 108-12.

Charpak N, Ruiz-Pelaez JG, Figuerora Z, Charpak Y. A Randomized Controlled Trial of Kangaroo Mother Care : Results of Follow Up at 1 Year of Corrected Age.

Alternative Way of Caring for Low Birth Weight Infants. One year Mortality in a Two Cohort Study. Pediatrics. 2001;108:5.

Christensson K, Bhat GJ, Amadi BC, Eriksson B, et al. Randomised study of skin-to-skin versus incubator care for rewarmingh low-risk hypothermic neonates. The Lancet. 1998;352.

Department of Reproductive Health and Research, World Health Organization. Kangaroo mother care. A practical guide. 1st ed. Geneva : WHO; 2003.

Dodd, V.L. (2003). Effects kangaroo care in preterm infants. University of Connecticut. . http://www.proquest.umi.com diperoleh tanggal 15 Januari 2014

Gillis.,L., A., Fairbanks., E., F., Crean., H., Small.,L., Sinkin., R., \& Xin T., et al (2006). Early InterventionProgramme Improves Health Of Babies And Parents. Diaksesdari 